\title{
Ultrastructural Localization of Enzymatic Activities in the Cells of the Digestive Glands of Drosera capensis L. during the Mucigenic Phase. Detection of Glucose-6-phosphatase Activity
}

\author{
Jean Dexheimer \\ Laboratoire de Botanique II, Université de Nancy I, case officielle \\ $n^{\circ} 140,54037$ Nancy Cedex, France
}

Received June 4, 1977

We have already published, as part of our study of the digestive glands of Drosera capensis, results concerning the various stages of the secretory phenomenon (Dexheimer 1976, Dexheimer 1978), and more recently on the ultrastructural localization of acid phosphatase activity (Dexheimer 1978). The present paper provides additional information on the localization of phosphatase activities in the digestive cells"during the mucigenic phase.

\section{Material and methods}

The glands, in the mucigenic phase, (Dexheimer 1976), were fixed with $2.5 \%$ glutaraldehyde maintainded at $\mathrm{pH} 7.2$ by cacodylate buffer. The specimens were then washed 3 times ( $3 \times 5$ minutes). After this, they were cold incubated for 3 hours and then for 1 hour at $37^{\circ} \mathrm{C}$ in Wachstein and Meisel's medium (Hayata 1973). The specimens were exposed to a vacuum at the start of both fixing and incubation in order to facilitate penetration of fixing solution or incubation medium.

After incubation, the specimens were washed several times with distilled water and then post-fixed with $2 \%$ osmium tetraoxid in phosphate buffer at $\mathrm{pH} 7.2$.

Composition of incubation medium

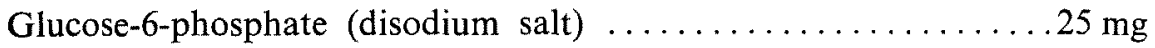

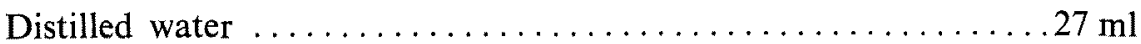

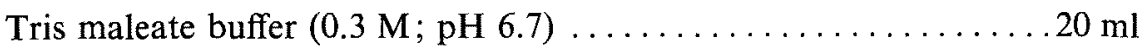

$2 \%$ lead nitrate solution $\ldots \ldots \ldots \ldots \ldots \ldots \ldots \ldots \ldots \ldots \ldots \ldots \ldots \ldots$

On adding the lead nitrate, the medium becomes cloudy. It should be kept in a refrigerator for one hour. We filtered off the precipitate just before use. The incubation medium was changed at the start of hot incubation.

The enzyme glucose-6-phosphatase is very sensitive to the fixing agents employed in cytology and with a view to testing this sensitivity, we used different times of exposure to glutaraldehyde: 5, 10, 15, 30 minutes, 1 and 4 hours.

Results were checked by repeating each fixing experiment at least 3 times.

The control samples used consisted of specimens incubated in substratum free medium and of the preparations where enzymatic activity had been inhibited by glutaraldehyde (see below Figs. 5 and 6). 


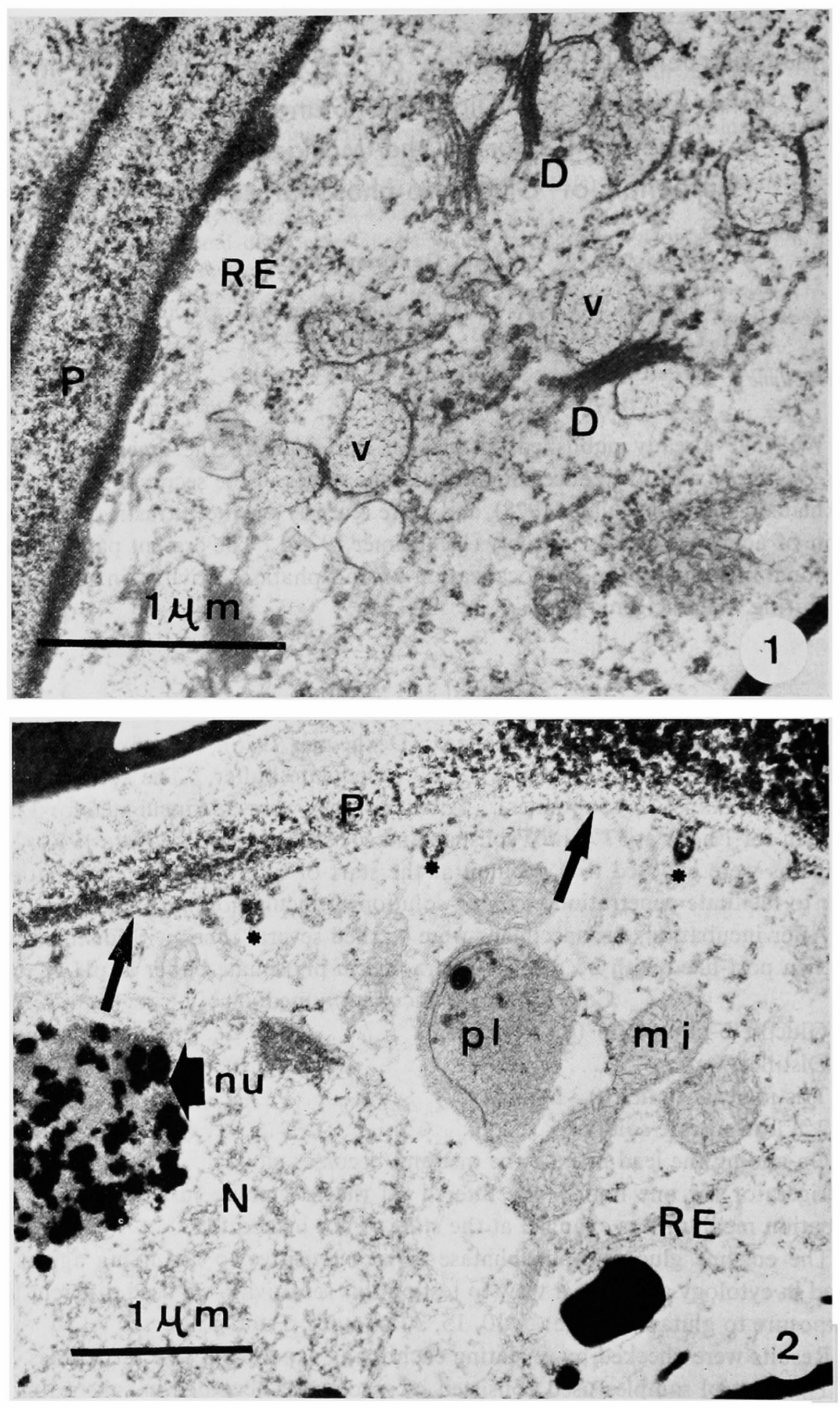




\section{Results}

No glucose-6-phosphatase activity was observed in the cytoplasm at any stage of secretion, neither in the endoplasmic reticulum, the mitochondria, nor the dictyosomes (Figs. 1 and 2). In most of the cells the nucleolus displayed very precipitation (Fig. 2).

A very marked reaction took place at the plasmalemma, this latter being edged with a continuous line of precipitated lead (Figs. 2 and 3).

The strongest enzymatic activity was revealed at the cell walls, but its distribution was not uniform and, in addition, varied according to the stage of secretion.

During the initial phase (Fig. 1), staining was very pronounced in the external parietal layer and undisinguishable from that of the plasmalemma. We had already noticed this layer (Dexheimer 1976) for it gives a very strong reaction in the Thiery test for polysaccharides and has a great affinity for ruthenium red and alcian blue. The rest of the cell wall is stained less strongly and more or less uniformly.

During the later phases (Figs. 2, 3, 4), the distribution of glucose-6-phosphatase activity was no longer the same. It was concentrated above all in the median part of the cell wall, where we have observed accumulation of mucilage, on either side of the middle lamella. This latter was not very reactive and stood out as a light area against the dark precipitate background.

The parietal digitations (the remains of the secretory vesicles) (Dexheimer 1976) were very active and contained a compact mass of precipitated lead (Figs. 2 and 3). We find, in agreement with those authors (Heinrich 1975, Halperin 1969, Roland 1969, Tice and Barrnett 1962) who have studied glucose-6-phosphatase activity before us, that this latter, survives only very short fixing times. The best results were obtained after 5, 10 and 15 minutes of fixing. After 5 minutes (Figs. 1 and 3), despite the short duration of fixing, cytoplasmic structure was perfectly preserved and enzymatic activity very strong. The activity was still considerable after fixing times of 10 (Fig. 4) or 15 (Fig. 2) minutes.

After 30 minutes, lead precipitation still takes place, but the reaction is much diminished (Fig. 5).

Finally, after longer fixing times (1 hour or 4 hours: Fig. 6), no glucose-6-phosphatases activity whatsoever was detected.

Abbreviations: D: dictyosome; mi: mitochondria; N: nucleus; nu: nucleolus; P: cell wall; pl: plastid; RE: endoplasmic reticulum; v: Golgi secretory vesicles. Figs. 1-2. 1, initial stage of secretion. The dictyosomes are very active and sprout large fibril-containing vesicles. Glucose6-phosphatase activity is very high along the outer part of the cell walls. The central part of the cell walls is much less active. $\times 34,000.2$, final stage of secretion. The secretory vesicles are reduced to parietal protuberances (stars). In the cytoplasm, only the nucleolus is stained. The plasmalemma is edged with a continuous line (arrows) of precipitated lead. The protuberances are also very active. In the cell wall proper, notice the migration of glucose-6-phosphatase into the median part. $\times 25,000$. 

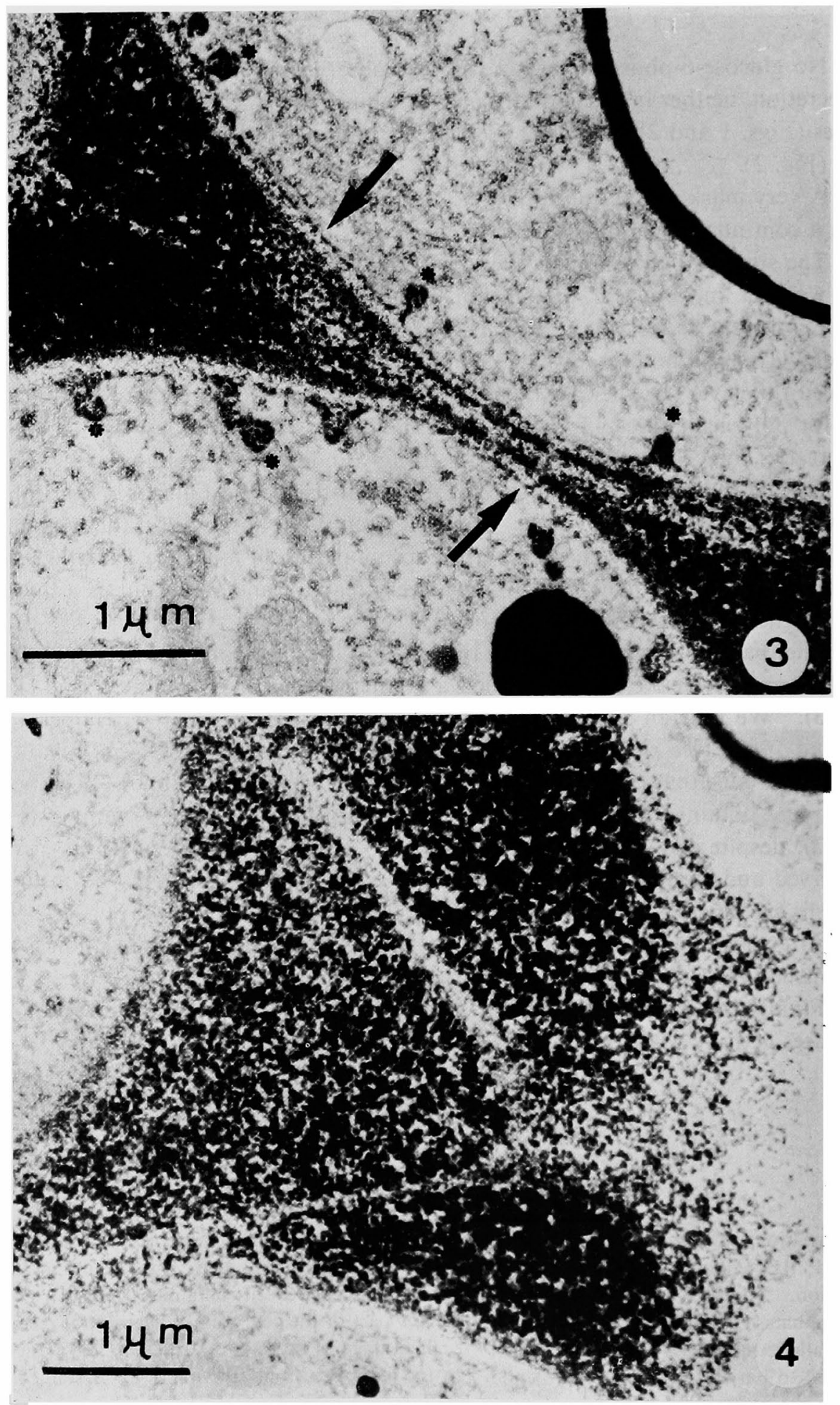


\section{Discussion and conclusion}

In this last section, we shall discuss, on the one hand, the specificity of the reaction observed, on the other, the significance of the localization of the glucose-6phosphatase activity.

Our experiments on fixing using different times $(5,10,15,30$ minutes, 1 and 4 hours) confirm the very great sensitivity of the enzyme to glutaraldehyde. Too long times of fixing ( 30 minutes and, above all, 1 and 4 hours) inhibit the glucose6-phosphatase activity. It will be recalled that if the other phosphatases are subjected to the same times of fixing, they still remain very strongly active.

These results argue in favour of the specificity of the reaction. After 1 or 4 hours of fixing, glucose-6-phosphatase is inhibited, but acid phosphatases are still active (Dexheimer 1978), yet we have never observed lead precipitation, which indicates that under our incubation conditions, the substratum can only be attacked by a specific enzyme, inhibited by glutaraldehyde: glucose-6-phosphatase.

Few authors have studied the ultrastructural localization of glucose-6-phosphatase activity in plant cells. We may mention the work of Roland (1969) on the growing collocytes of Ballota nigra and that of Heinrich (1975) on the nectaries of Aloe. Halperin (1969), in cultures of Daucus carota cells, used glucose-6-phosphate as substratum in Gomori incubation medium, but did not distinguish between glucose-6-phosphatase activity and acid phosphatase activity.

Roland (1969) observed that lead precipitation is localized in the endoplasmic reticulum and on the plasmalemma. In the nectaries of Aloe, Heinrich (1975) has detected glucose-6-phosphatase activity in the vacuoles, the endoplasmic reticulum, the mitochondrial membrane, along the plasmalemma, in the nuclear membrane and on the chromatin.

Work carried out on plant material has confirmed the localization of glucose6-phosphatase in the endoplasmic reticulum (cf. the work on animal material of Tice and Barrnett (1962) and of Leskes et al. (1971)) and even, in one case (Heinrich 1975) on the nuclear membrane. In addition, Heinrich and Roland have detected glucose-6-phosphatase activity on the plasmalemma. This has never been observed in animal cells.

In Drosera capensis, we have never found any activity in the endoplasmic reticulum, where as it is very high on the plasmalemma. The absence of activity in the endoplasmic reticulum seems to be in contradiction with the results of the authors just mentioned, but it should be borne in mind that very few glucose-6phosphatase tests have been carried out on plant cells and that our knowledge of sites of activity in cells as specialized as those of the digestive glands of Drosera is practically non-existent. In addition, in at least one publication on this subject Roland (1969), the photographs appended show that the reticular activity is con-

Figs. 3-4. 3, detail of a cell wall during the final stage. The plasmalemma (arrows) is very active. The zones where mucilage has accumulated (median part of the cell walls; protuberances: stars) show intense glucose-6-phosphatase activity. The middle lamella, much less active, shows up as a light area. $\times 25,000.4$, detail of junction between several cells at same stage as in Fig. 2 . The plasmalemma, cut obliquely, is not visible. The middle lamella, feebly active, stand out clearly against the mucilage. $\times 20,000$. 


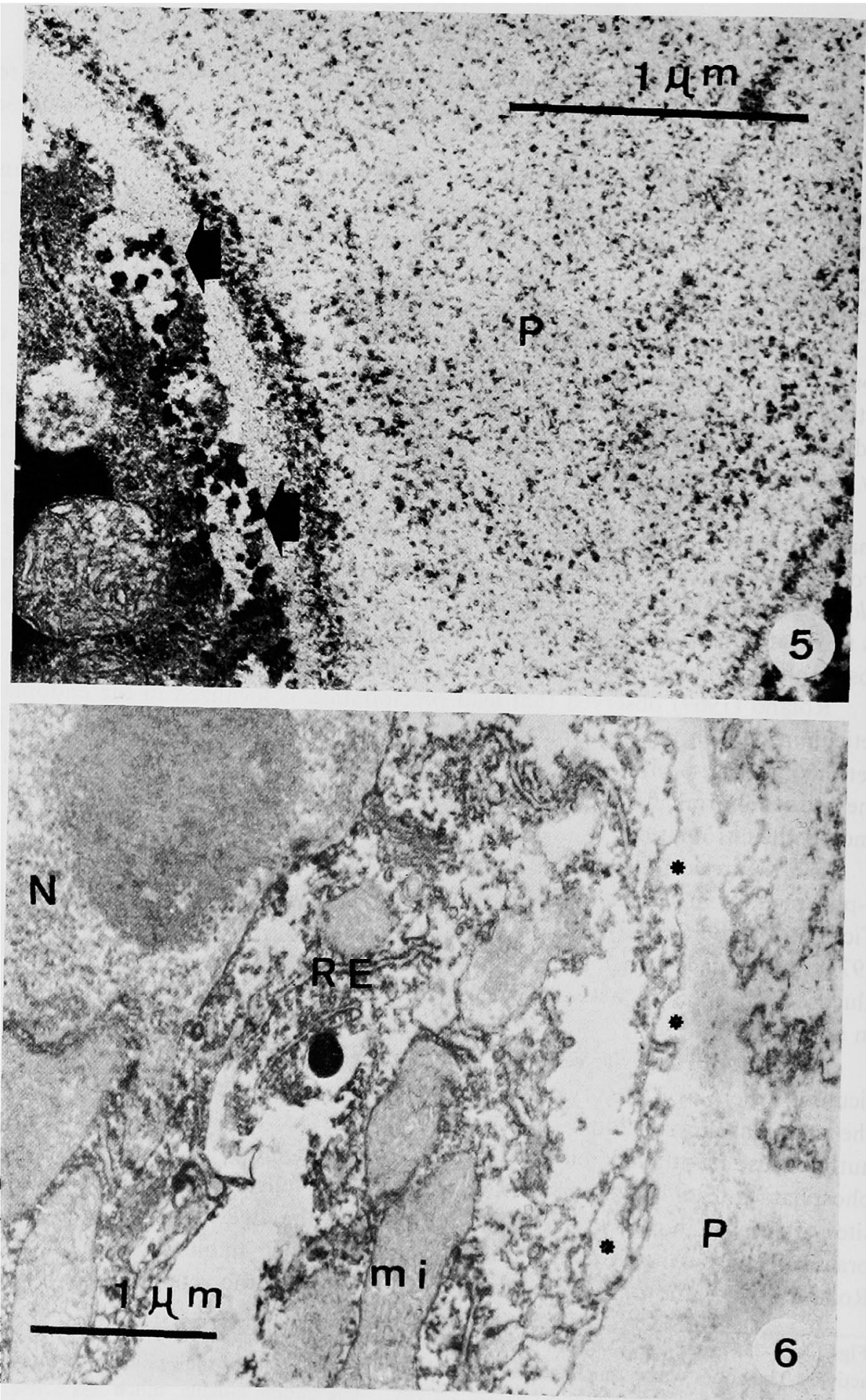


siderably less than that of the plasmalemma. It is probable, then, that in plant cells, the greater part of the glucose-6-phosphatase activity is concentrated on the plasmalemma.

Lead precipitation on the nucleolus was not observed by Roland (1969) and Heinrich (1975). However, Halperin (1969) has obtained images identical with ours, but with a non-specific reaction and using fructuose-1-6-diphosphate as substratum. In the present state of our work, it is not possible for us to interpret these images.

Finally, the cell walls displayed high enzymatic activity. This result is new, since no plant cell examined for this enzyme has shown activity in the cell wall. The fact that we find precisely the same lead precipitation distribution pattern in each of our fixed specimens eliminates the possibility of an artefact due to diffusion of the enzyme.

The greater part of the glucose-6-phosphatase activity in the cell walls of the digestive glands is associated with the mucilaginous exudation.

During the initial phase, when most of the mucilage is still in the Golgi vesicles or has only just been expelled from the cell, the glucose-6-phosphatase activity is very high in the external parietal zone. Later, the mucilage reaches the median parts of the walls and the enzymatic activity migrates with it, since it may be seen on either side of the middle lamella. The activity is also very high in the parietal digitations, which are remains of the secretory vesicles. It may be noted here that the parietal protuberances of the nectary cells of Aloe (Halperin 1969), morphologically identical with the Drosera digitations, do not show any activity.

Glucose-6-phosphatase is an enzyme which is associated with the active transport of sugars across cell membrane (Roland 1969) and its presence in the plasmalemma is not surprising, above all in cells engaged in polysaccharide synthesis as intense as that in Drosera cells during the mucigenic phase.

On the other hand, the very close like existing between the enzyme and the mucilage in the cell walls has never been described and its significance is not clear to us.

Thus, it emerges from our investigation that the reaction which we have employed is specific and that the glucose-6-phosphatase activity is very high in the plasmalemma and in the cell walls, where it is associated with the mucilage. Finally, the ultrastructural localization of this enzyme is very different to that of the acid phosphomonoesterases (Dexheimer 1978). Future work on the localizaton of the neutral phosphatases will complete this study of the localization of phosphatase activities in the cells of the digestive glands of Drosera during the mucigenic phase.

Figs. 5-6. 5, detail of a cell wall at the final stage. Fixed with glutaraldehyde for 30 minutes. The activity in the median part of the cell wall has considerably diminished (compare Fig. 4 which shows an identical zone fixed for 10 minutes). The protuberances still contain large-sized precipitates (arrows). $\times 40,000.6$, Overall view of a cell at the final stage. Fixed with glutaraldehyde for 4 hours. Lead precipitation is no longer observable since glucose-6-phosphatase activity has been completely inhibited. $\times 25,000$. 


\section{Abstract}

The object of this paper is to describe more precisely the ultrastructural localization of glucose-6-phosphatase activity in the cells of digestive glands of Drosera capensis during the mucigenic phase. The detection reaction is specific and very sensitive to fixing by glutaraldehyde.

At no time was any activity detected in the endoplasmic reticulum or the dictyosomes. As in all plant specimens studied previously, the plasmalemma was very active. However, the majority of the glucose-6-phosphatase activity was concentrated in the cell wall, in the zones where mucilage accumulate (parietal "protuberances", peripheral and median zones of the cell wall). It has not been possible to determine the significance of this localization.

\section{Bibliographie}

Dexheimer, J. 1976. Etude de la sécrétion de mucilage par les cellules des glandes digestives de Drosera ( $D$. rotundifolia $L$., et $D$. capensis $L$.). Application de quelques techniques cytochimiques. Cytobiologie 13: 307-321.

- 1978. Study of mcilage secretion by the cells of the digestive glands of Drosera capensis L. using staining of the plasmalemma and mucilage by phosphotungstic acid. Cytologia 43: $45-52$.

- 1978. Localization ultrastructurale des phosphatases acides (phosphomonoestérases acides) dans les cellules des glands digestives du Drosera capensis L. pendant la synthèse de mucilage. Rev. Cytol. Biol. Vég., Bot. 1 : 49-57.

Heinrich, G. 1975. Über die Lokalisation verschiedener Phosphatasen im Nektarium von Aloe. Cytobiologie 11: 247-263.

Halperin, W. 1969. Ultrastructural localization of acid phosphatase in cultured cells of Daucus carota. Planta 88: 91-102.

Leskes, A., Siekevitz, P. and Palade, G. E. 1971. Differentiation of endoplasmic reticulum in hepatocytes I. Glucose-6-phosphatase distribution in situ. Jour. Cell Biol., 49: 264-287.

Hayat, M. A. 1973. Electron Microscopy of Enzymes. Principles and Methods. Volume I. Edit.: Van Nostrand Reinhold.

Roland, J. C. 1969. Localisation d'acitivités enzymatiques au niveau des ultrastructures des collocytes en croissance de Ballota nigra. C.R. Acad. Sci. Paris 268: 2052-2055.

Tice, L. W. and Barrnett, R. J. 1962. The fine structural localization of glucose-6-phosphatase in rat liver. J. Histochem. Cytochem. 10: 754-762. 